\title{
Graphic organizers as a teaching strategy for improved comprehension of argumentative texts in English
}

Organizadores gráficos como estrategia didáctica para la comprensión de lectura de textos argumentativos en inglés

\section{Volumen 18, Número 2}

Mayo-Agosto

pp. 1-22

LATINDEX, DOAJ, REDIB, IRESIE, CLASE, DIALNET, SHERPA/ROMEO, QUALIS-CAPES, MIAR

Revista registrada en los directorios:

ULRICH'S $, \underline{R E D I E}, \underline{R I N A C E}, \underline{\text { OEI }}, \underline{\text { MAESTROTECA }}, \underline{\text { PREAL, }}$ 


\title{
Graphic organizers as a teaching strategy for improved comprehension of argumentative texts in English
}

Organizadores gráficos como estrategia didáctica para la comprensión de lectura de textos argumentativos en inglés

\author{
José Miguel Vargas Vásquez \\ Randolph Zuñiga Coudin ${ }^{2}$
}

\begin{abstract}
The University of Costa Rica seeks to prepare students for understanding academic texts in English by requiring reading comprehension courses in numerous degree programs. In this context, this paper aimed to assess the effectiveness of graphic organizers as a strategy to promote reading comprehension by focusing on the identification of rhetorical functions in argumentative texts. The paper followed an explanatory-sequential design within a mixed-methods approach with a group of 20 students at the Western Branch of UCR. To apply the strategy, three argumentative texts and their corresponding graphic organizers were used. The data consisted of performance scores and of answers to questionnaires. After the cycle of applications, the results showed a gradual improvement in the identification of rhetorical functions, particularly of arguments and counterarguments. Support for the author's arguments, rebuttals to counterarguments, and the author's overall claim were slightly more difficult to identify. The participants found graphic organizers helpful to better understand the parts of an argument in a text and its overall organization. At the same time, they found that the lack of explicit discourse markers and of familiarity with the content made understanding the connections between rhetorical functions difficult in spite of the help provided by the organizers. The study concluded that repeated implementation of graphic organizers has a positive impact on reading comprehension by helping students to read more strategically. However, accompanying strategies such as summarizing and discriminating main ideas from supporting details are necessary to complement the work with graphic organizers and improve their effectiveness.
\end{abstract}

Key words: English, reading comprehension, reasoning, visual representation.

Resumen: La Universidad de Costa Rica busca preparar a sus estudiantes, mediante cursos de comprensión de lectura en sus programas de estudio, para enfrentarse a textos académicos en inglés. . En este contexto, se pretendió evaluar la efectividad de los organizadores gráficos como estrategia para promover la comprensión de lectura, enfocándose en la identificación de funciones retóricas en textos argumentativos. La investigación siguió un diseño explicativo secuencial dentro del paradigma de método mixto con un grupo de 20 estudiantes en la Sede de Occidente. Para la aplicación, se utilizaron tres textos argumentativos y sus organizadores gráficos. Los datos consistieron en resultados del desempeño de los estudiantes y repuestas a un cuestionario. Tras las aplicaciones, los resultados mostraron una mejoría gradual en la identificación de funciones retóricas, particularmente de argumentos y contraargumentos. La evidencia para los argumentos, las refutaciones a los contraargumentos y la tesis del autor fueron relativamente más difíciles de encontrar. Las personas participantes afirmaron que esta estrategia les permitió entender mejor las partes de un argumento y la organización global del texto. Asimismo, indicaron que la falta de conectores explícitos y de conocimiento del tema dificultó comprender las relaciones entre las funciones retóricas en el texto. El estudio concluyó que la implementación repetida de la estrategia presentó un impacto positivo en la comprensión global del texto, ya que le ayudó al estudiantado a leer más selectivamente. Sin embargo, estrategias paralelas como resumir o discriminar ideas principales de las secundarias son necesarias para mejorar la efectividad de los organizadores gráficos.

Palabras clave: Inglés, comprensión de lectura, razonamiento, representación visual.

${ }^{1}$ Docente en la Sede de Occidente de la Universidad de Costa Rica, Sección de Lenguas Modernas. Magister en la Enseñanza del Inglés como Lengua Extranjera. Maestría en Enseñanza del inglés de la Universidad de Costa Rica. Dirección electrónica:jsmgvargas@gmail.com

2 Docente en la Escuela de Lenguas Modernas y en el Posgrado de Enseñanza del Inglés como Lengua Extranjera de la Universidad de Costa Rica. Magister en la Enseñanza del Inglés como Lengua Extranjera. Dirección electrónica: rzunigaco@gmail.com

Artículo recibido: 3 de noviembre, 2017

Enviado a corrección: 7 de febrero, 2018

Aprobado: 12 de febrero, 2018 


\section{Introduction}

The demand for reading comprehension in English at college level continues to increase given the status of English as the main international language of research and technology. According to a recent study, 32 degree programs at the University of Costa Rica require their students to take the courses LM-1030 and LM-1032, Reading Comprehension Strategies in English I and II respectively, to complete their studies (Moreira, 2016). The same study concludes that the courses, offered by the School of Modern Languages, are considered very important by most departments at the university since they help students to prepare for research in their fields and for advancement in their future professions.

The complexity of understanding technical texts in English makes the support of reading strategies necessary for many students who may not have the proficiency level expected for successfully tackling research in English in general, and the variety of texts covered in the reading comprehension courses specifically. At the University of Costa Rica, two studies have focused on the teaching of strategies in the reading comprehension courses in question. The first study, conducted by Zúñiga (2015), addressed the need for independent study in addition to classwork and for technological support as strategies for improving reading comprehension in English, specifically with the software called "Hot Potatoes". The results showed that electronic feedback had a positive effect on students' performance in classroom activities. The second study, conducted by Barrantes (2015), focused on the effectiveness of a cycle of activities consisting of graphic organizers and summaries. The author concluded that graphic organizers by themselves were not always sufficient to promote discrimination of main ideas from irrelevant details. Summaries subsequently emerged as a complementary strategy that helped students fill the gaps in comprehension left by the graphic organizers alone.

The studies surveyed above examined their respective reading strategies with the objective of determining their effectiveness to support reading comprehension. However, they did not focus on a particular type of text or genre. The researchers of this study believe that attention should be given to genre since awareness of the rhetorical structure used by different types of texts needs to be integrated into the work with reading strategies. In this respect, Nuttall (2000) proposes graphic representations of patterns of text organization as a useful strategy for unveiling the "relationships between parts of the text and their individual contributions to the whole" (p.109). In Nuttall's view, understanding the complex network of relationships in a text can be achieved, in part, by making explicit the corresponding rhetorical 
structure. These relationships are marked by the author's purpose and the type of text; therefore, the type of text plays an important role in how students tackle the information and achieve comprehension. If graphic organizers can help visualize how relationships are achieved in a specific type of text, they can be a very useful tool for understanding texts of a particular genre, especially when the genre grows in complexity.

One rhetorical pattern that has been particularly difficult for students in reading comprehension courses is argumentative discourse because of the complex relationships between the different sides of the argumentation. At the same time, argumentative texts are a key genre for students to understand. As Larson, Britt, and Larson (2004) assert, argumentative texts are not only required in a variety of high school and college assignments, but are also a frequent part of workplace situations in which decisions are made based on the ability to understand and support arguments (p. 205). For this reason, the researchers deem strategic support for understanding argumentative texts an urgent need for college students.

In light of the previous discussion, the aim of this study was to assess the effectiveness of graphic organizers as a strategy to identify the rhetorical functions representing the flow of ideas typical of argumentative texts through a series of applications of the strategy. It also aimed to gather students' perceptions of the possible advantages and disadvantages of graphic organizers for the proposed objective in order to fine-tune classroom procedures for working with the strategy, and thus, to support the overall teaching of strategies done in the reading comprehension courses at the University of Costa Rica.

\section{Review of literature}

\subsection{Reading strategies in foreign language learning}

In the academic world, reading is the main means for obtaining information and for learning. Due to the increasing number of scientific articles published in English, reading has increasingly become the main form of contact with this language. This allows everyone to have access to a vast array of knowings such as technological processes, scientific findings, and world events, among others. Through reading, students can be updated and participate more efficiently in a constantly evolving world.

In reading, the processing of texts occurs at two different levels: "top down" and "bottom up". Nuttall (2000) proposes that the comprehension of a text at the first level takes place in a global manner by means of conscious attention to text organization, to main ideas, and to the author's purpose. Through this approach, the relationship between text patterns can be 
analyzed and many of the schemata needed to understand a text can be activated. According to the author, top-down processing also provides the reader with an overall vision of a text, similar to that of a bird high above the ground. As for the second level, Nuttall points out that text processing is much more detailed and mainly focused on the analysis of words, phrases, and sentences in order to clarify gaps in understanding not covered by the expectations generated at the top-down level (p.17). These two levels of processing interact constantly to achieve complete understanding of a text. Thus, not only is it necessary to understand the vocabulary in a text to be able to identify its organization, but also to activate previous knowledge of text structure which can compensate for the vocabulary that the reader does not know.

Readers achieve fluency when they have acquired enough linguistic knowledge and reached an understanding of the most important elements of the text. Saville-Troike (2006) strongly emphasizes the need to deepen the knowledge of vocabulary, grammar, and text structure to recognize them automatically without conscious attention (p.156). Conscious attention can limit the speed of comprehension and negatively affect the understanding of the author's purpose, hence the importance of practice in reading and of the systematization of examples leading to the more fluent understanding of a text.

Reading is also a social and intentional action since it requires the use of strategies that simplify the interaction with the text. Maira Solé (2007) proposes that reading should be conceived as a strategic act and a personal and willful activity, in which the readers should behave differently depending on the type of text, the author's purpose, and the topic (p.2). This intentionality can be put into practice through a set of procedures to help students interact with a text. Here, the strategic success of the readers relies on their understanding of the context variables involved, in combination with a meaningful selection of procedures for approaching the text. Similar to Solé, Gill (2008) claims that

...comprehension can be affected by the reader's interest in the background knowledge of the topic, by strategies the reader knows how to use, and even by the reader's physical and emotional self-image. Style, layout, and organization of the text; difficulty of vocabulary, concept load, and even the presence or absence of illustrations can also affect students' comprehension. (p. 108)

This author also claims that a way to reduce text difficulty is to create a comprehension matrix with a pre, while, and post-reading cycle where different reading strategies can be 
used accordingly to ensure strategic instruction. During the pre-reading, for example, instructors can provide a purpose for reading and analyze the layout of the text, of the title, and of the illustrations. In the while-reading phase, a more in-depth analysis of text organization and vocabulary can be carried out. Finally, in the post reading, strategies for solidifying and extending understanding can be implemented. Implicit in these recommendations is the notion that effective reading comprehension occurs as the result of a series of steps in which readers interact with the text and not as a single action taking place at once.

To guarantee that there is interaction between the reader and the text, An (2013) highlights the role of schema theory in reading comprehension. She proposes that a reader is involved in a process of constructing meaning through the interaction of pertinent schemata and elements of the text and that these different types of schemata should be activated: formal schemata related to the rhetorical structure of the text; content schemata related to the content of the text; and cultural schemata related to the cultural information needed to understand the text (pp. 130 131).

For the purpose of this study, formal schemata are key to decoding the meaning of a text. Since different texts have different rhetorical patterns, the ability to identify the structure of the text can contribute to understanding its message. There are different types of texts: expository, narrative, argumentative, and procedural, among others, each with different patterns of organization; for example, general to specific, claim-counterclaim, and narrative, among others. Understanding this organization is a condition for effective communication and for the development of reading comprehension skills.

In light of the previous discussion, second language reading tasks must involve the use of strategies that provide opportunities to use linguistic knowledge, to identify main ideas and details, to recognize patterns of organization, and to analyze relationships between ideas. These strategies must guide readers to acknowledge the type of text and its content and to recognize the different levels of schemata involved in comprehension. Lastly, reading strategies should be embedded in a cycle of reading comprehension (pre-while-post) and promote different types of information processing.

\subsection{Graphic organizers}

Graphic organizers have been implemented in a variety of fields like the social sciences, chemistry, and education, among others, for different uses such as testing 
background knowledge, planning for a task, illustrating a system, solving a mathematical problem, and testing reading comprehension. Coburn (2003) defines graphic organizers as

... diagrams that represent the relationships between facts, ideas, and concepts. They come in many forms, including flowcharts, webbing, concept mapping, and matrixes. They are not organized in a linear format according to a sequence like traditional outlines; instead, they convey relationships through a visual format that are linked and ordered through a conceptual framework. (p. 46)

This flexibility is what makes graphic organizers easy to adapt for different purposes and what allows learners to identify different patterns of organization and to establish relationships between concepts and ideas.

The ability to establish connections behind the concept of graphic organizers is grounded on a theory of cognitive processing called connectivism. This theory focuses on "the increasing strength of associations between stimuli and responses rather than on the inferred abstraction of 'rules' or on restructuring." Thus, a strengthening of these associations is the core of the learning process from a connectionist point of view (Ghaemi and Fakhraee, 2011, p.45). A graphic organizer stresses concepts and their relationships, allowing students to focus on the most important information to arrive at an overall understanding of the entire text. Thus, successful use of graphic organizers should lead to students being able to interpret and summarize correctly the input that they are exposed to. When a learner is able to connect what she or he has read to her/his prior knowledge and identify relationships between both sets of information, then graphic organizers have successfully assisted in the learning process.

To guarantee the effectiveness of graphic organizers, Merkley and Jefferies (2000) have proposed a series of guidelines. Four of these guidelines are presented here:

1. Verbalize relationships: The teacher should emphasize the links between the concepts of the text accurately. This can be done by highlighting key ideas and words from the reading selection.

2. Provide opportunity for student input: The teacher should use the elements of the graphic organizer for discussion allowing student input.

3. Connect new information to past learning: The teacher should use the graphic organizer as part of a cycle of activities and should present it in relationship with a topic that has 
already been discussed in class or with a topic that students can relate to their previous knowledge so that it can be used to establish connections.

4. Seize opportunities to reinforce decoding and structural analysis: Graphic organizers are particularly good for studying technical vocabulary and for analyzing the structure of a text; thus, teachers should stress these aspects in the organizers. This should be done in a way that is not complicated for the learners while making sure that the graphic organizer is indeed representative of the text.

Graphic organizers should be framed in a cycle of activities (pre-while-post). McTighe (cited in Praveen and Premalatha, 2013) has proposed that before instruction, graphic organizers be used to assess the level of the students in terms of understanding. During instruction, thinking is supported by graphic organizers allowing students to explore the content from a cognitive angle. After instruction, organizers help students to summarize the text and to assess their own improvement (p.156). The implementation of the cycle should go hand in hand with a series of suggestions. To this effect, Egan (1999) proposes that graphic organizers be used to promote interaction among students and to set a clear learning goal. Also, she recommends regular implementation, for lack of familiarity with the format of the organizers may result in students not knowing how to work with them.

\subsection{Reading Comprehension of Argumentative Texts}

Argumentative texts are probably one of the most challenging types of texts that learners are confronted with. In addition, they are an essential part of academic and professional life. According to Larson, Britt, and Larson (2004), "students read and understand arguments in a variety of classroom situations and must prepare to continue this practice in the workplace and in real-life decision making scenarios" (p.205). Argumentation, then, requires analyzing the validity of ideas and putting arguments to the test to be able to develop informed opinions and to make decisions in a variety of contexts well beyond the classroom.

Given the importance of this genre and in light of its structure, it is necessary to define its elements. The model followed for this study is that described by Weida and Stolley (2017):

1. Claim: The overall thesis the writer will argue for.

2. Arguments for the claim: Evidence gathered to support the claim.

3. Support: Explanation of why or how the data support the claim. 
4. Counterclaim: A claim that negates or disagrees with the thesis/claim.

5. Rebuttal: Evidence that negates or disagrees with the counterclaim.

Out of all these elements, identifying the author's claim in a reading selection is both the most important and the most challenging task. Since the other arguments in the text are presented either as support or as opposition to this claim, an error in its identification can lead to confusing the complete argumentative flow of the text. The possibility needs to be considered that a negative response towards a claim or a misidentification of its position in the text can be influenced by the reader's social and cultural schemata given the different existing patterns of argumentation.

Larson, Britt, and Larson (2004) conducted a study on the difficulties that learners often face when reading this type of texts. They carried out an experiment with sixty-seven Englishspeaking students from an introductory level psychology class at Northern Illinois University, where participants were asked to identify arguments in excerpts from a series of naturally occurring texts. The authors found that the students who scored low in the experiment required help from the instructor, in the form of discourse markers or argument structure training, for example. These features are probably the two most frequent obstacles encountered by students when dealing with argumentative reading tasks. In this area, the researchers of the current study propose that the most effective solution is explicit instruction on text structure. Discourse markers by themselves may not be effective in all possible cases as they can be used for other rhetorical functions- not necessarily related to the argumentative flow of the text.

In addition to the aforementioned difficulties, Reznitskaya, Anderson, and Kuo (2007) emphasize another challenging aspect of argumentative texts: the dialogical nature of argumentation, where arguments and counterarguments may clearly emulate a conversation. This duality in the text can be perceived in the flow of arguments and counterarguments and can be made visible through graphic organizers.

Newell, Beach, Smith, and VanDerHeide (2011) propose that social and cognitive variables interact in a model for comprehension of argumentative texts. Here literacy plays a significant role in the understanding of a text and its functions. This should be integrated into the instruction of argumentative reading and used to gain knowledge of a text. A step by step protocol can help to identify the location where the different argumentative functions are found and also, help alleviate the cognitive difficulty of a text. This, in turn, can help learners 
to reconstruct the complete argumentative chain and to develop a better sense of audience. The comprehensive visual support inherent to graphic organizers can make them a useful tool to fulfill the protocol and achieve the overall reading comprehension goal.

\section{Methodology}

The present study followed a mixed methods design of the type defined by Creswell (2014) as explanatory sequential design. In this design, quantitative research and an analysis of its results are carried out first. Then, a qualitative follow-up attempts to explain the quantitative results, hence the term "explanatory". The division of the procedure into the two steps accounts for the term "sequential" (pp. 15-16). The quantitative step in this study consisted of the implementation of graphic organizers in class, followed by the analysis of the scores obtained by the participants and by the application of a closed-answer questionnaire. The qualitative follow-up consisted of the analysis of the participants' answers to a series of open-ended questions.

\subsection{Participants}

The participants were a group of 20 students in the course LM-1030, Reading Strategies in English I, consisting of 11 males and 9 females, with ages ranging from 17 to 23 years old. Out of the total number of students, seventeen were enrolled in the Computer Science program, two in the Chemistry Laboratory program, and one in the Natural Resources Management program at the Tacares campus of the University of Costa Rica. The students were the main actors in the process. They had to work individually to identify the expected elements of the rhetorical organization of the texts and to reflect on their own learning in order to assess the effectiveness of graphic organizers as an aid for reading comprehension.

\subsection{Instruments}

\subsubsection{Texts}

Three argumentative essays written in English were employed for developing the graphic organizers and other reading tasks in the classroom. The texts were selected from current online newspapers and were not simplified in terms of vocabulary, content, or organization. The only change made to the texts was the division into clearly numbered paragraphs for the purpose of guiding the students through the tasks. The topics covered 
were "social mobility in the United States", "debunking myths of milk consumption", and "the Japanese whaling industry". The extension of the texts ranged between 1119 and 1229 words.

\subsubsection{Graphic organizers}

Three semi-complete graphic organizers were given to the students. The graphic organizers represented the argumentative flow of the entire text in each case. The graphic organizers included the following elements of argumentative texts: author's claim, arguments for the author's claim, support, counter arguments, and rebuttals. The graphic organizers indicated the number of the paragraph where the information was meant to be retrieved. Because of the different length and organization of the texts, the graphic organizers were not designed with exactly the same number or distribution of missing elements to be identified.

\subsubsection{Questionnaire}

The goal of the questionnaire was for students to assess their own learning and the perceived effectiveness of the graphic organizers. The questionnaire contained two sections: closed and open answer. The first section addressed the students' perceived level of improvement and the most challenging the most challenging tasks required for completing a graphic organizer. Students had to state their answers on a Likert scale. The second section contained questions for the participants to elaborate on the perceived strengths and drawbacks of graphic organizers. The questionnaire was applied after having completed the three sessions with the strategy (See appendix A).

\subsection{Procedures}

The strategy implemented for this project was a graphic organizer reflecting the rhetorical flow of an argumentative essay with a claim and counterclaim structure. The organizer was partially completed to aid students with comprehension of the text. Both the empty and the completed spaces contained the number of the paragraphs where the expected answers were meant to be retrieved. The strategy was applied on three different occasions and consisted of three structured stages: pre-reading, while-reading, and postreading.

To determine the effectiveness of graphic organizers, the number of correctly and incorrectly identified responses was counted for each of the functions of argumentative texts 
included in the organizers. This was done to determine if the total number of correctly identified responses increased by the end of all the sessions and also, to determine how the number of correctly identified responses varied for each function.

As for the students' perception of the effectiveness of the strategy, their responses in the Likert scale were averaged to determine the mean scores reflecting the group's perception of their improvement in identifying rhetorical functions and of the most challenging aspects of the task. In addition, the open answers from the questionnaire were classified into advantages and disadvantages and analyzed by the researchers.

\subsubsection{Stage I: Pre-reading}

In the first session, the elements of argumentative writing were explained; particular attention was given to the discourse markers often used to introduce each of the functions: author's claim, arguments for the author's claim, support for arguments, counterarguments, and rebuttals. The need to understand the relationship between ideas both explicitly and implicitly in order to complete the graphic organizer was emphasized by the researchers. In addition to this, the title and the topic of each text were discussed with the help of the first few sections of the corresponding graphic organizer in order to activate the students' background knowledge and to give them hints about the organization of the text in question.

\subsubsection{Stage II: While-reading}

Individually, students read the article and completed the graphic organizer accordingly.

\subsubsection{Stage III: Post-reading}

In pairs, students compared their responses. Then, in a guided session, the students checked that their choices corresponded to the discourse flow of the text. The researchers stressed the identification of linguistic evidence for the correct recognition of all the functions involved. Moreover, they examined the relationship between the author's claim and the rest of the argumentation.

\section{Results and discussion}

\subsection{Assessment of graphic organizers from a quantitative perspective}

At the end of the three sessions with graphic organizers, total numbers for the correct identification of the rhetorical functions involved were calculated, and percentages 
representing the total identification of each function were drawn. These percentages are presented in Table 1.

Table 1. Percentage of recognition of rhetorical functions in an LM1030 group at the University of Costa Rica, Western Branch, I semester, 2016

\begin{tabular}{|c|c|c|c|}
\hline$\underline{\text { Rhetorical function }}$ & $\underline{\text { Session } 1}$ & Session 2 & $\underline{\text { Session } 3}$ \\
\hline Author's claim & 50 & 60 & 65 \\
\hline Argument & 85 & 90 & 70 \\
\hline Support for argument & N.A. & 50 & 92,5 \\
\hline Counterargument & 90 & 92,5 & 85 \\
\hline Rebuttal & 56,7 & 60 & 82,5 \\
\hline
\end{tabular}

Source: Own elaboration based on the data collected, May 2016.

The results for identification of author's claim show that the percentage increased progressively from one session to the next. This is a positive result given that correct identification of author's claim is the first step towards comprehension of the complete text and thus, its misidentification could lead to disorientation with the overall flow of ideas. The relative difficulty of identifying the overall claim may be reflected in the numbers not being very high, but the results can still be considered positive because they suggest that the strategy slowly helped the students improve their performance on a difficult task.

As for identification of arguments, the results seemed positive for the first two sessions as they yielded relatively high percentages of correct identification and an improvement from one session to the next. In the third session, however, identification of arguments dropped, reflecting an inconsistency in the effectiveness of the strategy for this rhetorical feature. $A$ closer examination of the results in this case showed that the argument with the lowest percentage of identification was placed later in the text than the arguments in the first two sessions, which appeared as the first argument supporting the author's claim. A possible explanation for the lower results in the third session may be that the different location of arguments could have affected the identification of this function.

The graphic organizer used in session 1 did not include the identification of author's support as one of the rhetorical functions that students needed to identify. In this case, and since it was an initial stage of the application of the strategy, the function was included explicitly in the graphic organizer. The aim was to help students visualize part of the flow of ideas in the text and to lessen task difficulty in the first application. In the following sessions, students were asked to identify this rhetorical function by themselves; the results show a 
marked increase from a relatively low number in session 2 to a satisfactorily high number in session 3. In this sense, the result for this rhetorical function can be considered very positive.

The results for identification of counterarguments were relatively high and the most stable throughout the sessions although they decreased slightly in the last session. This suggests that counterarguments were the rhetorical function for which the graphic organizers used in the study were at their most effective. The combined results for identification of individual arguments and counterarguments compared to those for the author's claim also seem to suggest that the latter poses a greater degree of difficulty for students given that its numbers are considerably lower. This may point to the identification of the overall purpose of an argumentative piece being a more complex task than that of single, more isolated arguments and counterarguments.

The results for identification of rebuttals start at a relatively low level similar to those for author's claim. Even though they experience a considerable increase by the third session, they are still lower than those for counterarguments in every case. This is noteworthy since typically, rebuttals are closely linked in the text to the counterarguments that originate them; the results appear to contradict expectations that identification of rebuttals should parallel that of counterarguments.

All together, these results show that graphic organizers used for identifying the rhetorical functions in argumentative texts appear to be more effective for identification of arguments and counterarguments than for overall author's claim, support for individual arguments, and rebuttals.

In the following step, students were asked to complete two scales to assess their own learning and the perceived effectiveness of the graphic organizers once all the sessions had been completed.

The first scale consisted of the perceived benefits of graphic organizers. For this, students had to assess the extent to which the graphic organizers contributed to identifying each of the elements of argumentative texts. The scale consisted of 5 levels; 5 represented remarkable improvement and 1 no improvement at all. The scores from the answers were averaged to establish the group's relative degree of understanding. Table 2 shows that students see their improvement as slightly superior to the middle point of the scale.

Table 2. Average score of students' perception of the benefits of graphic organizers in an LM1030 group at the University of Costa Rica, Western Branch, I semester, 2016 
The graphic organizer helped me identify ...

Average score

the author's purpose and position

3,2

the author's arguments for his position

3,45

the counterarguments

3,35

the rebuttals to the counterarguments

3,25

the overall text organization

3,3

Source: Own elaboration based on the data collected, May 2016.

The best rated items were identification of the author's arguments and of the counterarguments. At the same time, identification of the author's claim and of rebuttals was rated slightly lower. These results are consistent with those of the application of the graphic organizers, which pointed to greater difficulty in identifying those two functions.

Table 3 shows the results of the second scale, which focused on the perceived difficulties in performing specific tasks necessary for completing the graphic organizers with the argumentative text. This scale also contained 5 levels; 1 represented not challenging at all and 5 very challenging.

Table 3. Average score of students' perception of difficulties in completing graphic organizers in an LM1030 group at the University of Costa Rica, Western Branch, I semester, 2016

\begin{tabular}{ll}
\hline \multicolumn{1}{l}{ Ifound it challenging to... } & Average score \\
\hline identify main ideas and specific details & 2,9 \\
identify main ideas in different types of paragraphs & 3,15 \\
summarize information & 3,45 \\
understand the topic of an essay & 3,2 \\
\hline
\end{tabular}

Source: Own elaboration based on the data collected, May 2016.

The results show that the most challenging tasks for students were understanding the overall topic of an essay and summarizing information. Identifying main ideas in different types of paragraphs and identifying main ideas and specific details were rated as slightly easier. In this instrument, different types of paragraphs referred to paragraphs not presenting the topic sentence first. Concerning the most challenging task, it appears that even though paragraph numbers had been added to the graphic organizers to lessen task difficulty, students still found it challenging to select and summarize pieces of information necessary for the solutions to the tasks. This points to an interdependence between summarizing 
information and the use of graphic organizers given that the subskill of summarizing plays an important part in their success while at the same time it is supported by their completion. In turn, this suggests a need for training the students in summarizing before attempting to work with graphic organizers.

As for the task of understanding the overall topic of the essay, the rating as slightly more difficult seems consistent both with the scores of the graphic organizers, which reflected less success in identifying the author's overall claim in argumentative texts, and with the results in Table 2, which also yielded a lower score for identification of the author's claim.

\subsection{Assessment of graphic organizers from a qualitative perspective}

The previous analysis concluded the quantitative section of the study. In the qualitative section, students' answers to the open-ended questions yielded that from their perspective, graphic organizers are very effective to understand text organization. The most salient result is that the majority of students responded that they were able to identify both sides of the argumentation and that graphic organizers have made them aware of the rhetorical organization of the text. This broadly corresponds to the results of the quantitative analysis showing that graphic organizers help to identify arguments and counterarguments. However, most students felt that additional practice was necessary to successfully master the strategy.

In the open-ended questions, students also took the opportunity to describe perceived difficulties that they experienced and the usefulness of graphic organizers for their comprehension of argumentative texts. From these answers, a series of perceived advantages and disadvantages emerged. The following sections present the researchers' analysis of the students' responses.

\subsubsection{Advantages}

Based on students' responses, graphic organizers allowed them to achieve a better understanding of text organization because they reveal the structure of the text and the possible different forms of organization in an easy-to-grasp visual manner. This perception can be linked to the positive results obtained for identification of the two sides of an issue, at least from a general point of view. The graphic organizers appear to provide readers with a previous insight of how arguments are structured; through the illustration of the organization of the text, they are likely helping students make use of different types of textual and possibly content schemata to confront the text before they engage in the reading process. 
An additional benefit expressed by the students is that graphic organizers helped them distinguish between main ideas and supporting details. This matches the scores obtained by this function in the survey, which indicated that it was less challenging for the students than other functions. According to this, graphic organizers seem to help students make a more selective reading and set priorities for approaching the text. This can simplify the reading process and provide support, particularly for students with a lower command of the language.

Further, students explained that graphic organizers were useful for understanding more easily how the text switches from one argument to another. Again, they mentioned the visual representation of the argumentative flow of ideas as the factor contributing to lessening the difficulty of the text, both before and while reading.

Finally, students reported that their overall comprehension of the text had also improved through graphic organizers since the opportunity to visualize the structure of the arguments had compensated for their lack of vocabulary. In the survey, the usefulness of graphic organizers to promote overall comprehension of the text obtained an intermediate rating, lower than for arguments and counterarguments, but higher than for author's purpose and rebuttals. The combination of both results may suggest that for students with a lower command of the language, graphic organizers work both for helping to understand a text better in a general way and for providing a certain sense of motivation. However, they may not fully allow students to clearly distinguish all of the finer elements necessary to understand the author's position and the rebuttals.

\subsubsection{Disadvantages}

Students' responses to the open-ended questions revealed that in spite of the help provided by the graphic organizers, they still had some trouble identifying the author's main claim. These responses are consistent with previous results showing that identification of overall claim had weaker scores in the implementation of graphic organizers and also weaker scores in the survey. This difficulty may be due to students confusing the claim with the background knowledge, especially when the author does not make a personalized claim about the topic or when the claim is not in the first paragraph. Another problem may surface when the introduction contains a counterargument making the author's position more difficult to distinguish.

Another disadvantage identified by students was that even with the graphic organizer, they found it difficult to identify argumentative relations when there were no explicit 
connectors to indicate opposing ideas. In such cases, attention to other sentence elements is required for students to be able to make a correct inference about the flow of argumentation. This, combined with lack of vocabulary and of knowledge of other linguistic elements may be at the root of the difficulty

The problem of making inferences was addressed in further answers pointing to the difficulty of classifying information when the topic is unknown or unfamiliar. These students indicated that lack of familiarity with the topic often led them to make wrong inferences about the text and to confuse the evidence provided. In these situations, students seem to feel that the graphic organizers were not able to help them to understand the texts in more detail. This, in turn, may be linked to the result showing that summarizing information was perceived as the most difficult function to perform. The effect may result from lack of familiarity with the topic making it more difficult for the students to understand the content and thus, to decide what information to pay attention to for inclusion in the summary. In some cases, ideas were copied and pasted literally rather than being condensed, which does not reflect positively the students' understanding of the text.

Lastly, students expressed as an obstacle to comprehension that on occasions, they found it difficult to recreate the thought sequence needed to construct the outline of the graphic organizer. Specifically, they reported that they saw the organization of the text slightly different from the intended, and that this made it challenging for them to reorganize their own ideas so that they would fit into the organizer.

\section{Conclusions}

Overall, the study yielded that students perceived graphic organizers as effective for the purpose intended, but they required additional practice with the strategy, and probably, more experience with argumentative discourse. The results suggest that students would be able to work with graphic organizers better once they have learned to identify main ideas and supporting details. In addition, gaps in the students' familiarity with the topics may negatively affect the results as the ability to infer correctly, often necessary for the successful completion of graphic organizers, appears to be affected by available schemata. Thus, success with graphic organizers seems to be affected by missing previous knowledge.

The results of the present study shed light on the challenges faced by students when attempting to understand the argumentative chain in a text with the help of graphic organizers. Correct identification of arguments and counterarguments in the text were the two 
functions that seemed easiest to perform from the beginning. Somewhat unexpectedly, identification of specific support for the author's arguments, of rebuttals to the counterargument, and of the author's overall claim seemed to pose a greater difficulty at the initial stage. However, students' performance in the identification of these functions improved throughout the cycle, suggesting that the repeated implementation of graphic organizers can indeed help students to learn how to approach a text more strategically and gradually improve their reading comprehension skills. The results suggest that students can more easily identify the different sides of an argument in a general way, but still struggle to understand how information is interconnected at a more specific level and how it all combines to support the author's purpose for writing the argumentative piece. Nonetheless, as there was a steady improvement even for this last function throughout the cycle, the researchers believe that repetitive practice with the strategy does have a positive impact.

The most beneficial and the most challenging aspect of graphic organizers were probably one and the same: the visual representation of the text. On one hand, it provided students with an effective tool to confront the text and to extract information; it also helped students make a more selective reading by highlighting the most important elements of the text and their relationship to one another. On the other hand, students may find it challenging to complete a preset representation of the text that does not necessarily reflect their own expectations of a rhetorical pattern based on their previous knowledge. In addition, graphic representations of a text for classroom instruction are necessarily adapted to the varying patterns of organization used by different authors to achieve their purpose. This variability can represent an additional challenge for students, particularly in the early stages of using the strategy of graphic organizers to analyze texts.

The present study is not complete without a discussion of limitations and recommendations for future studies. The use of authentic texts, while widely promoted by experts for reading lessons, can introduce a limitation to the work with graphic organizers as these texts do not always follow the more fixed patterns of argumentation found in standard academic essays. At the same time, if lessons do not focus on authentic texts, reading practice may not support reading comprehension in real-life scenarios. Thus, in spite of the additional difficulty posed by variability, graphic organizers should still be based to a great extent on authentic texts. To ensure their success in helping students to develop reading skills, they must be carefully designed to account for the particular rhetorical flow of each text under study. A further limitation was posed by the absence of a diagnostic test to determine 
the students' language level at the beginning of the implementation cycle of graphic organizers. The heterogeneous composition of the group places a limitation on the interpretation of the results because the individual characteristics of the students likely led to different perceptions both of the benefits and the difficulties of working with graphic organizers. Future studies may explore the relationship between the students' individual proficiency and their perception of the usefulness of the strategy as well as the effect of proficiency on the identification of specific rhetorical functions.

\section{References}

An, Shuying. (2013). Schema Theory in Reading. Theory and Practice in Language Studies, $3(1), 130-134$.

Barrantes, Daniela. (2015). Effectiveness of the Use of Graphic Organizers and Summaries: A Case Study of Adult EFL Students in a Reading Comprehension Course. Revista de Lenguas Modernas, (22), 267-295.

Coburn, Daniel. (2003). Using graphic organizers. Science Scope, 27(1), 46-48.

Creswell, John. (2014). Research design: Qualitative, quantitative, and mixed methods approaches $\left(5^{\text {th }}\right.$ ed.). Thousand Oaks, CA: Sage Publications.

Egan, Margaret. (1999). Reflections on effective use of graphic organizers. Journal of Adolescent and Adult Literacy, 42(8), 641-645.

Ghaemi, Farid, and Fakhraee, Laleh (2011). Connectionist models: Implications in second Language acquisition. BRAIN. Broad Research in Artificial Intelligence and Neuroscience, 2(3), 45-51.

Gill, Sharon. (2008). The comprehension matrix: A tool for designing comprehension instruction. The Reading Teacher, 62(2), 106-113.

Larson, Meredith, Britt, M. Anne, and Larson, Aaron. (2004). Disfluencies in comprehending argumentative texts. Reading Psychology, 25(3), 205-224.

Merkley, Donna, and Jefferies, Debra. (2000). Guidelines for implementing a graphic organizer. The Reading Teacher, 54(4), 350-357.

Moreira, Yamileth. (2016). Teaching English reading strategies to students of other majors at the University of Costa Rica. Revista de Lenguas Modernas, (24), 275-293.

Newell, George, Beach, Richard, Smith, Jamie, and VanDerHeide, Jennifer. (2011). Teaching and learning argumentative reading and writing: A review of research. Reading Research Quarterly, 46(3), 273-304. 
Nuttall, Christine. (2000). Teaching reading skills in a foreign language. Thailand: Macmillan Education.

Praveen, Sam, and Premalatha, Rajan. (2013). Using graphic organizers to improve reading comprehension skills for the middle school ESL students. English Language Teaching. $6(2), 155-170$.

Reznitskaya, Alina, Anderson, Richard, and Kuo, Lit-Jen. (2007). Teaching and learning argumentation. The Elementary School Journal, 107(5), 449-472.

Saville-Troike, Muriel. (2006). Introduction to second language acquisition. United Kingdom: Cambridge University Press.

Solé, Maira. (2007). Consideraciones didácticas para la aplicación de estrategias de lectura. Actualidades Investigativas en Educación, 7(3), $1-15$. 10.15517/aie.v7i3.9280

Weida, Stacy, and Stolley, Karl. (2017). Organizing your argument. Retrieved from https://owl.english.purdue.edu/owl/resource/588/03/

Zúñiga, Juan. (2015). El apoyo al estudio independiente en un curso de comprensión de lectura con "Hot Potatoes". Revista de Lenguas Modernas, (22), 317-334. 


\section{Appendix A: Questionnaire}

\section{Self-evaluation of the activity}

\section{Student:}

\section{Part I. Rating}

1. After having practiced completing outlines of argumentative essays three times, please mark the number that best describes your opinion about your perceived improvement. Use a scale from 1 to 5, 1 being "no improvement at all" and 5 "remarkable improvement". The graphic organizer helped me identify ....

\begin{tabular}{|c|c|c|c|c|c|c|}
\hline a. & & 1 & 2 & 3 & 4 & 5 \\
\hline b. & The author's purpose and position & & & & & \\
\hline C. & The author's arguments for his position & & & & & \\
\hline d. & The counter arguments & & & & & \\
\hline e. & The rebuttals to the counter arguments & & & & & \\
\hline f. & The synthesis of the argumentation & & & & & \\
\hline g. & The overall organization of the text & & & & & \\
\hline
\end{tabular}

2. During the classes, the following aspects were identified as challenging. How was it for you to ....

Use a scale from 1 to 5, 1 being "not challenging at all" and 5 "very challenging" .

\begin{tabular}{|c|c|c|c|c|c|}
\hline & 1 & 2 & 3 & 4 & 5 \\
\hline a. $\quad$ Identify main ideas and specific details & & & & & \\
\hline b. $\quad$ Identify main ideas in different types of paragraphs & & & & & \\
\hline c. Summarize information & & & & & \\
\hline d. Understand the topic of an essay & & & & & \\
\hline e. $\quad$ Other? & & & & & \\
\hline
\end{tabular}

I think that ...

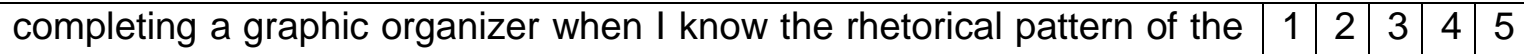
text is much easier than when I don't know the rhetorical pattern 


\section{Part II. Open answer}

1. I liked that by using this strategy I was able to

2. When completing the graphic organizer, I found it difficult to

3. Overall, how effective has this strategy been for you to improve the comprehension of an argumentative text? 